\title{
Microphorella cassari sp. n., a new species of Microphorella Becker (Diptera: Dolichopodidae) from Tunisia
}

\author{
Paul GATT \\ Research Associate, Institute of Earth Systems, Chemistry Building $3^{\text {rd }}$ Floor, \\ University of Malta, Msida MSD 2080, Malta. \\ E-mail: paulgatt@onvol.net
}

\begin{abstract}
Microphorella cassari sp. nov., a new species of Microphorella Becker (Diptera: Dolichopodidae) from Tunisia. - A new species of Micro phorella Becker, Microphorella cassari sp. n., is described from Tunisia. The strikingly long, strap-like, lanceolate antennal stylus and the long, spine-like setae on the mid-portion of the costal vein of the male are unique amongst previously described species of Microphorella. Likewise, the completely divided sternite 10 of the female has not hitherto been recorded in other species of this genus.
\end{abstract}

Keywords: Diptera - Dolichopodidae - Parathalassiinae - new species Mediterranean.

\section{INTRODUCTION}

Microphorella Becker is one of a small group of genera, both fossil and extant, which are currently placed in the subfamily Parathalassiinae of the Dolichopodidae s. lato (Ulrich, 2003; Sinclair \& Cumming, 2006). This almost cosmopolitan genus presently comprises 16 species of which 5 are Nearctic (Melander, 1928), 5 Palaearctic (Chvála, 1988; Gatt, 2003; Shamshev, 2004), 5 Oriental (Shamshev \& Grootaert, 2004) and 1 Australian (Colless, 1963). Three species - M. curtipes (Becker, 1910) (Corsica \& Sardinia), M. ulrichi Gatt, 2003 (Tunisia \& Morocco) and M. merzi Gatt, 2003 (Malta, Cyprus \& Turkey) - are currently known from the Mediterranean, the latter two exclusively so. Undescribed species are known from the Mediterranean (Gatt, in prep.) and it appears that this subregion is more diverse in species than previously thought.

Species of Microphorella are minute, cryptic flies with inconspicuous habits and which blend perfectly well with their surroundings (sandy beaches, gravel and sand in river beds, and moist rocks in streams). They are therefore not often collected, and very rare in collections.

\section{MATERIAL AND METHODS}

All specimens were collected by the author from coastal sand dunes or estuaries in two different localities in the Tabarka embayment (northwest coast of Tunisia) in the spring of 2005 and 2007. Most specimens were collected by lying prone on the sand and carefully aspirating the minute flies as they appeared. Some were collected by sweeping very close to the sand using slow, deliberate movements. 
Dissected specimens on which the drawings are based are stored in glycerine microvials mounted on pins in the author's collection. Temporary slide mounts of insect parts were prepared in Berlese fluid, as described by Disney (1983). Drawings were made with the aid of a 250 stereomicroscope and drawing tube. For some figures (Figs 6-8, 13) a compound microscope with built in ocular grid was employed. Drawings of complex structures made from slide mounts studied in transmitted light (eg. Fig. 5) fail to make a clear distinction between internal and external structures, and cannot show how the various parts are interconnected.

In descriptions of the abdomen and hypopygium, the terms "dorsal" and "ventral" refer to the morphological position after genital rotation and flexion, i.e. as they appear in the intact specimen.

The following abbreviations are used in the text figures 1-13:

as accessory sclerites of genital fork (sternite 9)

C female cercus

$\mathrm{Ce}$ male right cercus

ds dorsal sclerite of genital fork

EA ejaculatory apodeme

EPA epandrium

fo $\quad$ foramen from segment 8

HA hypandrium

hs10 female abdominal hemisternite 10

ht10 female abdominal hemitergite 10

$\mathrm{PH}$ phallus

$\mathrm{S}$ spermatheca

s1-s8 abdominal sternites 1-8

t1- t8 abdominal tergites $1-8$

vs ventral sclerite of genital fork (sternite 9)

The holotype labels are cited verbatim. The text of each separate label is enclosed in quotation marks, whilst individual lines on each label are separated by slash lines.

Specimens are deposited as indicated by the following acronyms in brackets under 'material examined':

IRSNB Institut Royal des Sciences Naturelles, Bruxélles, Belgium

MHNG Museum d'histoire naturelle, Genève

NMWC National Museum Wales, Cardiff

PGS Private collection of P. Gatt, Sliema, Malta

ZIN Zoological Institute of the Russian Academy of Sciences, St. Petersburg

ZMHB Museum für Naturkunde, Berlin (Zoologisches Museum der Humboldt Universität Berlin)

The terminology used in this account follows Merz \& Haenni (2000). Homologies for the male terminalia follows Sinclair (2000). 


\section{TAXONOMIC TREATMENT}

\section{Microphorella cassari $\mathrm{sp} . \mathrm{n}$.}

Figs 1-13

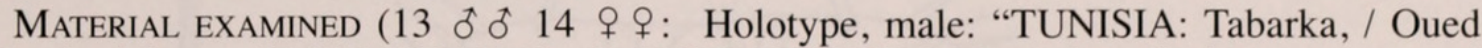
Berkoukech, / dunes, 31.iii.2007 / P. Gatt", "HOLOTYPUS / Microphorella / cassari sp. n. / Gatt." (IRSNB). The holotype is preserved in alcohol and is in perfect condition. - Paratypes, 9 to and 12 $q$ same data as holotype: $1 q$ Tunisia, Tabarka: Oued Berkoukech, beach, 13.iv. 2005, P. Gatt; 2 ơ oे, Tunisia, Tabarka, Oued Bouterfess, beach, estuary, 14.iv. 2005, P. Gatt; 1 ot and 1 ㅇ , Tunisia, Tabarka, Oued Bouterfess, dunes, 31.iii.2007, P. Gatt (IRSNB, MHNG, NMWC, PGS, ZIN, ZMHB). Paratypes are preserved in alcohol or dry (double mounted on pins)

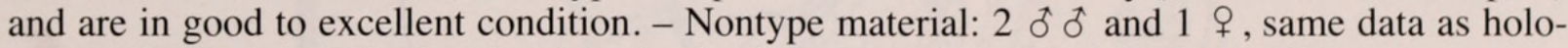
type; 1 \& , Tunisia, Tabarka, Oued Berkoukech, estuary, 13.iv.2005, P. Gatt (PGS).

ETYMology: This species is dedicated to my dear friend and colleague Dr. Louis F. Cassar who introduced me to the type locality, and in the company of whom I have spent many happy hours of fieldwork in North Africa.

DiAGNOSIS: A small (1.3 mm), brownish-grey microtrichose, sexually dimorphic species with white, lanceolate macrosetae and infuscated wings. Male: antennal style long, strap-like, acuminate; fore and mid tibia, posteriorly, with long setae; mid femur ventrally with a dense tuft of very short setulae and some long setae; mid basitarsus ventrally with a long row of hook-like spinules; anterior costal margin with spine-like setae. Female: tergite 10 and sternite 10 completely divided; tergite 10 bearing setae.

\section{DESCRIPTION}

\section{Male}

Length. Body $1.3 \mathrm{~mm}$, wing $1.2 \mathrm{~mm}$ (specimen in alcohol).

Head (Fig. 1). Black in ground colour, brownish-grey microtrichose, higher and wider than deep. Eyes widely separated on frons, ommatidia equal in size, sparsely covered with minute ommatrichia. Neck inserted high on head. Occiput greyish-brown microtrichose with some metallic reflections, scarcely projecting beyond posterior margin of eye, concave above neck, convex below. Gena very narrow. Face silvery grey microtrichose, long and narrow, narrower than frons above antennae, widening below. Clypeus grey microtrichose, long and convex. Antenna (Fig. 2) black, brownish microtrichose and clothed with short, pale setulae; placed at middle of head in profile, and as long as head is deep; scape cup-shaped; pedicel globular, with a circlet of subapical setulae; postpedicel long, bulbous in distal half and bearing a sensory pit at both ends; stylus uniarticulate, long and strap-like, subequal in length to pedicel, widening apically and terminating acutely; postpedicel and stylus covered with adpressed, spinelike microtrichia. Proboscis short, lustrous brown, projecting downwards. Palpus small, greyish microtrichose, with several long apical setulae and one longer seta on lateral surface; sensory pit present. Chaetotaxy: cephalic setae white, thick and flattened, somewhat lanceolate; one pair of strong, lateroclinate anterior ocellars; one pair of weak, proclinate posterior ocellars; one pair of inclinate anterior fronto-orbitals; one pair of lateroclinate posterior fronto-orbitals; one pair of long, inclinate medial verticals; one pair of shorter, lateroclinate lateral verticals; postocular occipital setae uniserial above neck, becoming longer and irregularly multiserial below; several longer setae present just posterior to mouth opening, including postgena.

Thorax. Black in ground colour, generally grey microtrichose; scutum slightly brown microtrichose anteriorly, with some faint metallic reflections; dorsal surface of 

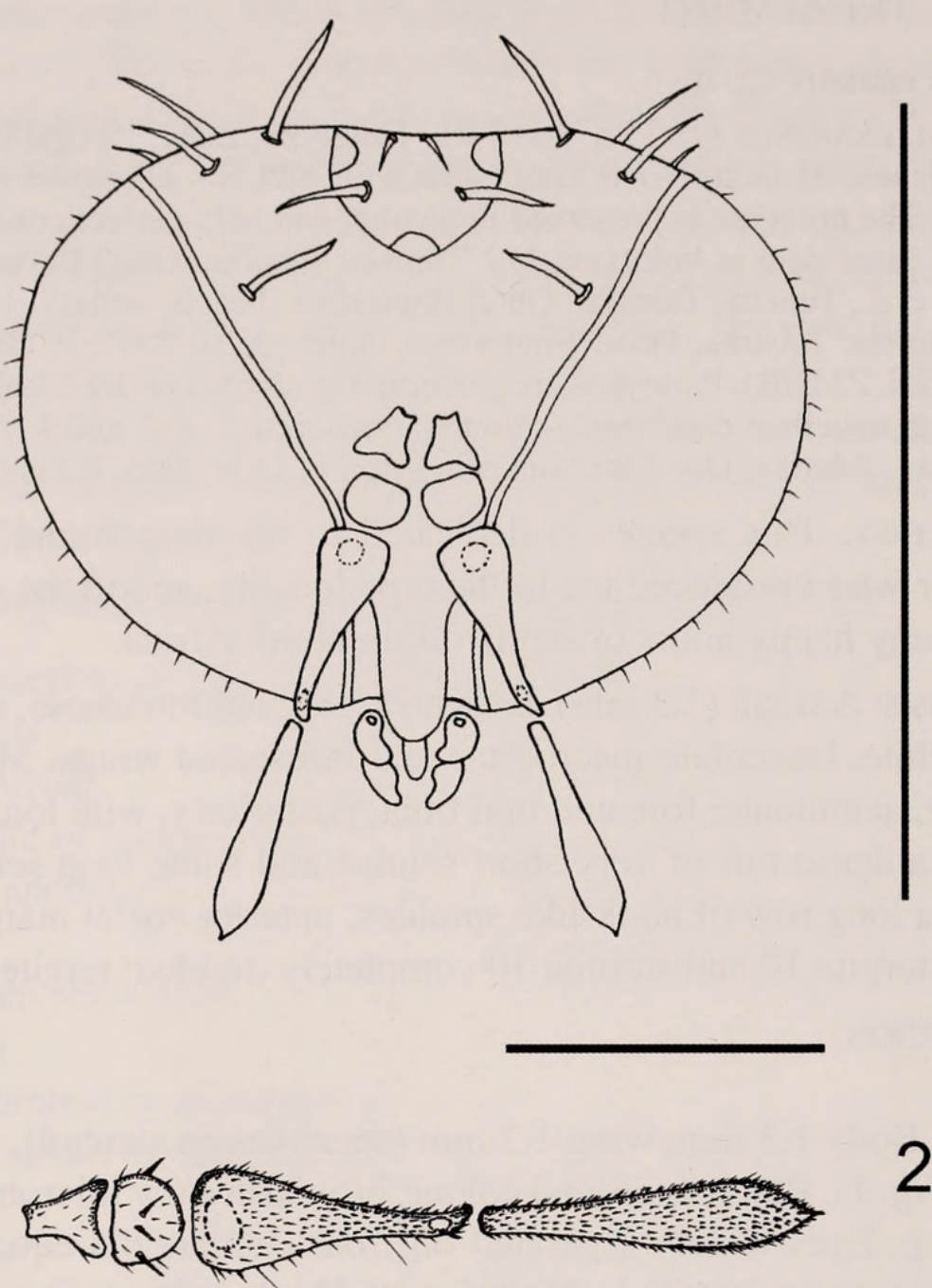

2

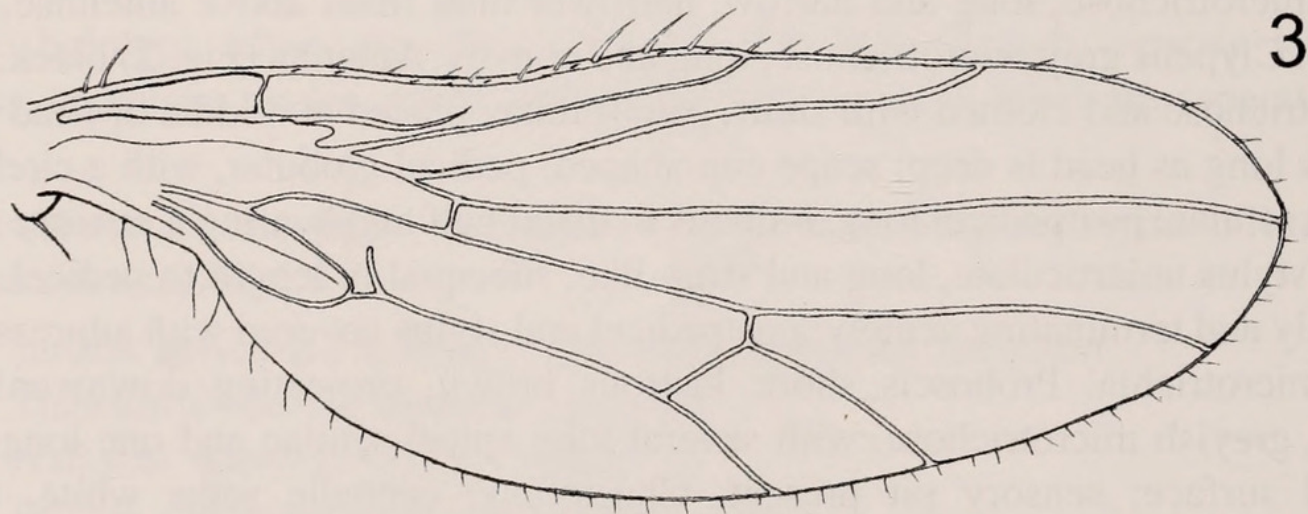

FIGS 1-3

Microphorella cassari sp. n. (1) ô head, viewed from above and in front. (2) ot antenna, lateral view. (3) ô, wing. Scale bars, Figs 1 and 3: $0.5 \mathrm{~mm}$, Fig. 2: $0.2 \mathrm{~mm}$.

mesoscutum moderately arched; prescutellar depression distinct; complete prothoracic precoxal bridge present. Mesopleuron bare, greyish brown microtrichose. Chaetotaxy: thoracic setae white, thick and flattened. Antepronotum with 4 setulae. Propleuron with 


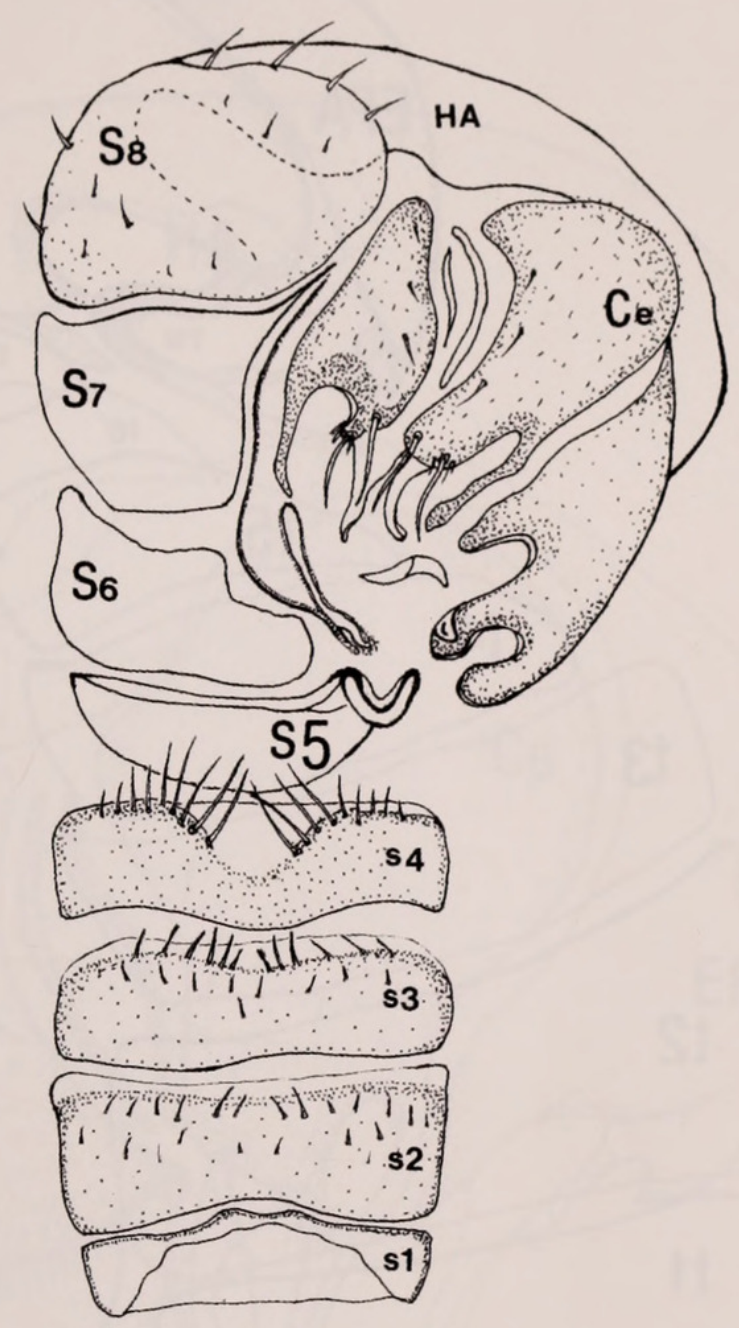

FIG. 4

Microphorella cassari sp. n., ठิ, abdomen, ventral view. Scale bar $0.5 \mathrm{~mm}$. Abbreviations explained in the text.

one pair of setulae. Postpronotum with 1 setula. A single pair of long, acrostichal setae on anterior slope of mesoscutum. Five $(2+3)$ pairs of subequal dorsocentral setae, 1 prescutellar pair longer, wider apart, and as strong as 1 pair of long, inclinate scu tellar setae; dorsocentral setae sometimes preceded by 1-2 setulae; additional setulae (2-3) sometimes present outside dorsocentral row on intra-alar line; 1 strong supra-alar seta, preceded by a row of 2-3 setulae; 1 postalar seta; 2 notopleural setae.

Legs. Long and slender, black in ground colour, greyish microtrichose and clothed with very short, white setulae; trochanters, apices of femora and all tibiae and tarsi paler. Femora equally thick, not much stronger than tibiae. Basitarsi as long as following tarsal segments combined. Coxae (especially fore pair) with some longer setae. Hind trochanter with 1 long, ventral seta. All tarsomeres with short, spine-like 


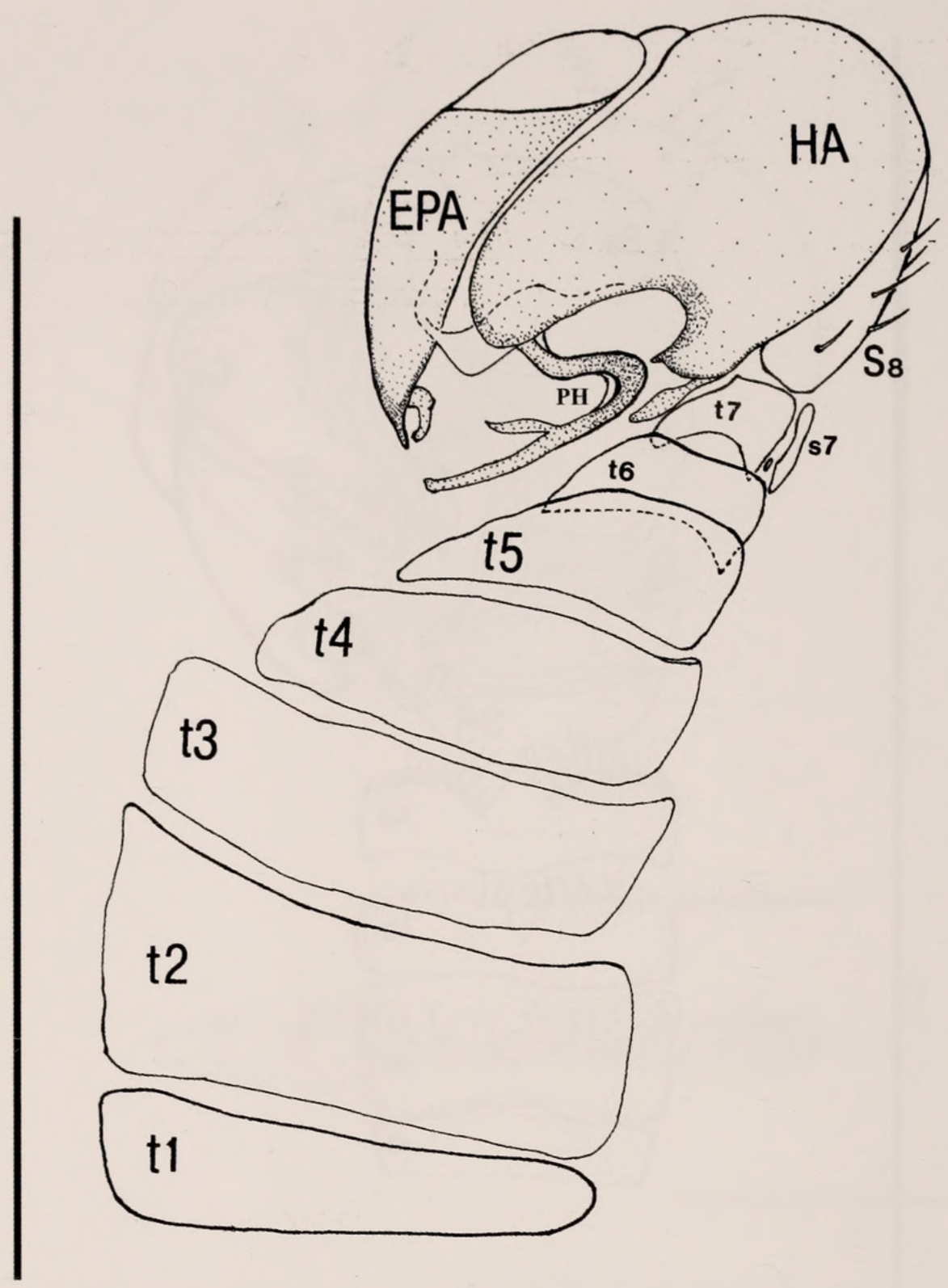

FIG. 5

Microphorella cassari sp. n., $\delta$ abdomen, dorsal view. Scale bar $0.5 \mathrm{~mm}$. Abbreviations explained in the text.

subapical setae, stronger and in groups of 4 on middle segments. Tarsal claws, pulvilli and empodium developed on all legs; pulvilli and empodium haired. Fore tibia with a posterior row of 8-10 long posteriorly curved setae, becoming shorter apically; bearing anterior apical comb; pigmented spinulated tubercles absent. Mid femur with a dense tuft of very short setulae along middle third of ventral surface, and with a fringe of some 8 long, pale, ventral setae, as long as or longer than femur is deep. Mid tibia with a posterior row of 4 long setae, and one spine-like subapical seta. Mid basitarsus with 2 spine-like setae ventrally at base; curved, convex laterally, and with a long row of some 23 short ventral spinules having curved, hook-like apices. Hind leg simple. Hind femur with a dorsal row of longer setae. Hind tibia with an apical posterior comb of closely set spinules. Hind basitarsus with an apical posterior comb of short setae. 


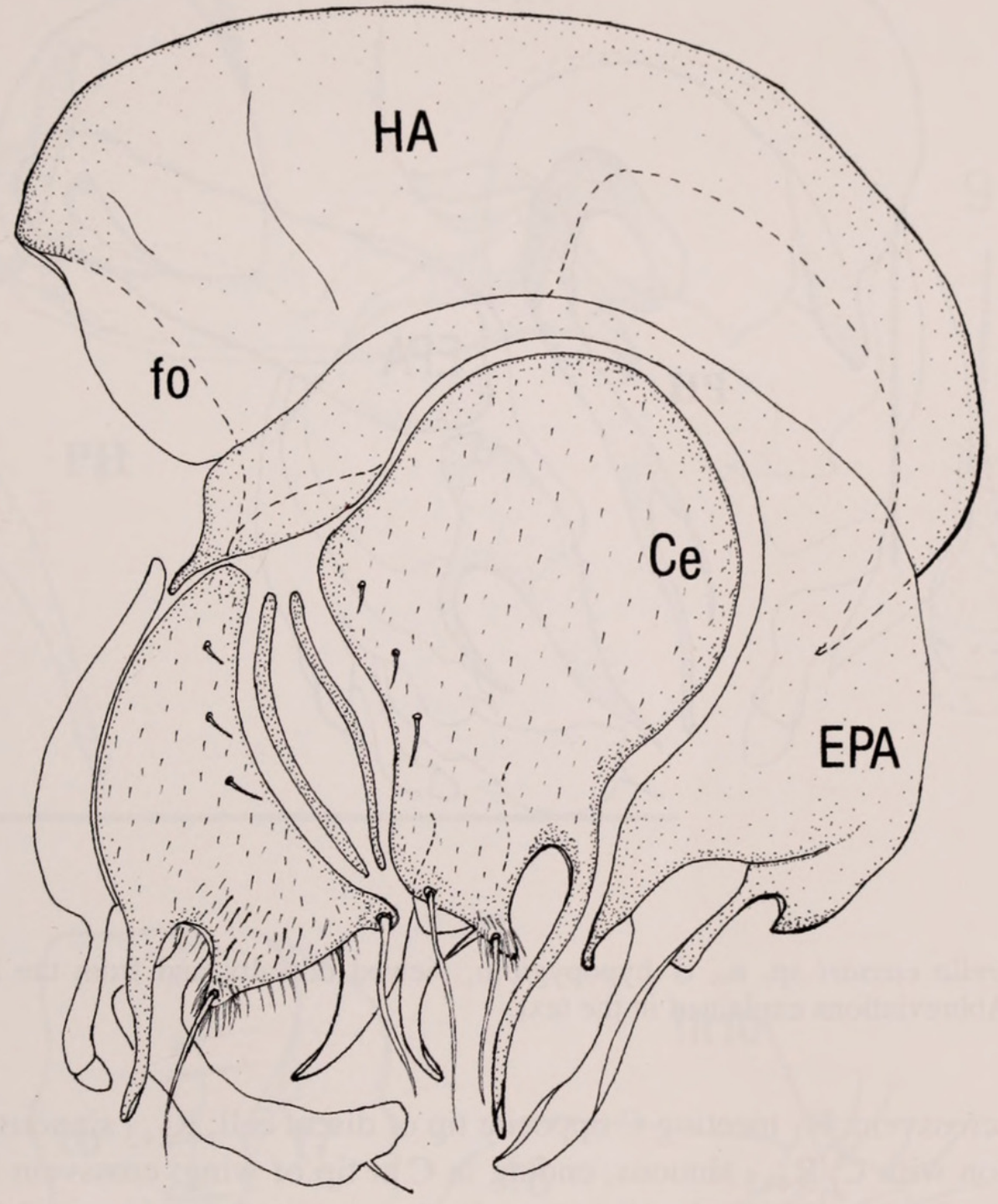

FIG. 6

Microphorella cassari sp. n., ô, hypopygium, viewed ventrally and from the right. Scale bar $0.2 \mathrm{~mm}$. Abbreviations explained in the text.

Wing (Fig. 3). Two and a half times longer than broad, axillary lobe hardly developed; wing membrane brown, darker on anterior half of wing, covered with microtrichia (including veins); macrosetae white; hind marginal fringe longest at base of wing; wing veins brown, stigma absent; $\mathrm{C}$ circumambient; $\mathrm{C}$ with 2 strong basal setae, anterior costal margin with a row of spine-like setae, longer and stronger at middle of wing; Sc parallel to $\mathrm{R}_{1}$, upturning to $\mathrm{C}$ before merging imperceptibly into membrane very close to $\mathrm{R}_{1}$; humeral crossvein indistinct; $\mathrm{R}_{\mathrm{S}}$ originating opposite 


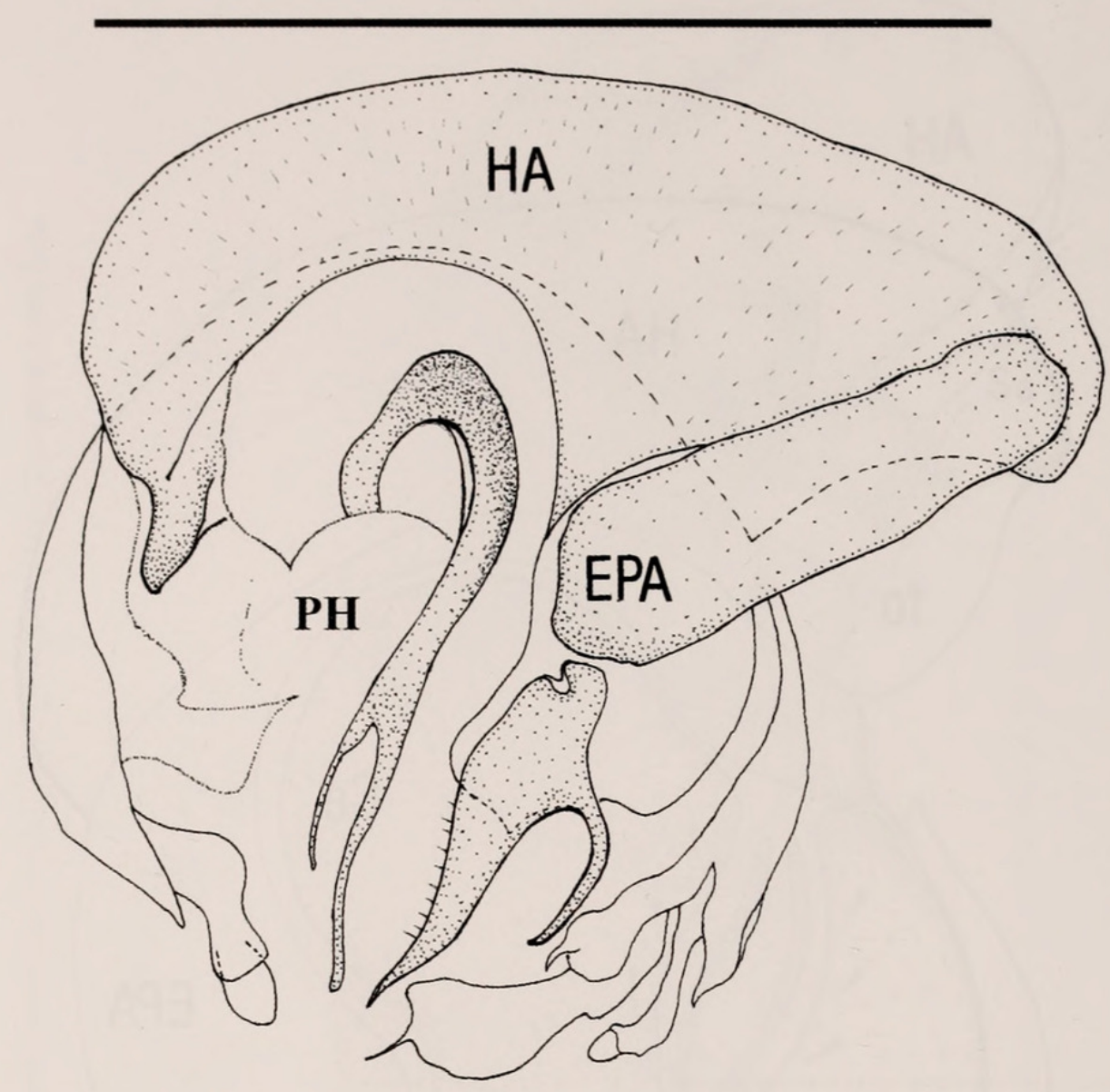

FIG. 7

Microphorella cassari sp. n., o hypopygium, viewed dorsally and from the left. Scale bar $0.3 \mathrm{~mm}$. Abbreviations explained in the text.

humeral crossvein; $\mathrm{R}_{1}$ meeting $\mathrm{C}$ opposite tip of discal cell; $\mathrm{R}_{2+3}$ sinuous, upcurved at its junction with $C ; R_{4+5}$ sinuous, ending in $C$ at tip of wing; crossvein $R-M$ present, sometimes indistinct; discal cell incompletely separated from second basal cell by incomplete crossvein $\mathrm{BM}-\mathrm{Cu}$, closed distally by crossvein $\mathrm{DM}-\mathrm{Cu}$ and emitting 3 veins to wing margin; base of $\mathrm{M}_{2}$ complete; crossvein DM-Cu complete; $\mathrm{CuA}_{2}$ curved, $\mathrm{A} 1+\mathrm{CuA}_{2}$ absent. $\mathrm{A}_{2}$ present. Alula absent. Squama brown, short, with a fringe of long, pale hairs. Haltere brown, stem darker than knob, the latter large and quadrate.

Abdomen (Figs 4-5): Brownish black in ground colour, less intensely grey microtrichose than thorax, rather subshining; sclerites with sparse, white setulae on posterior margins and on disc. Abdominal muscle plaques distinct. Tergites 1-4 and sternites 1-3 simple, unmodified. Postabdomen beginning with sternite 5 , rotated and lateroflexed to the right. Sternite 1 very short, narrowly sclerotised only on posterior and lateral margins, bare except for a covering of microtrichia. Sternites 2 and 3 setulose on disc especially along posterior margins; sternite 4 with a posteromedian membranous area, fringed on either side with a number of long setae. Sternite 5 short, bare, with a robust, well sclerotised posteromedian projection. Sternites 6 and 7 bare, simple. Sternite 8 large, subrectangular; tergite 8 atrophied. Terminalia (Figs 6-7) 

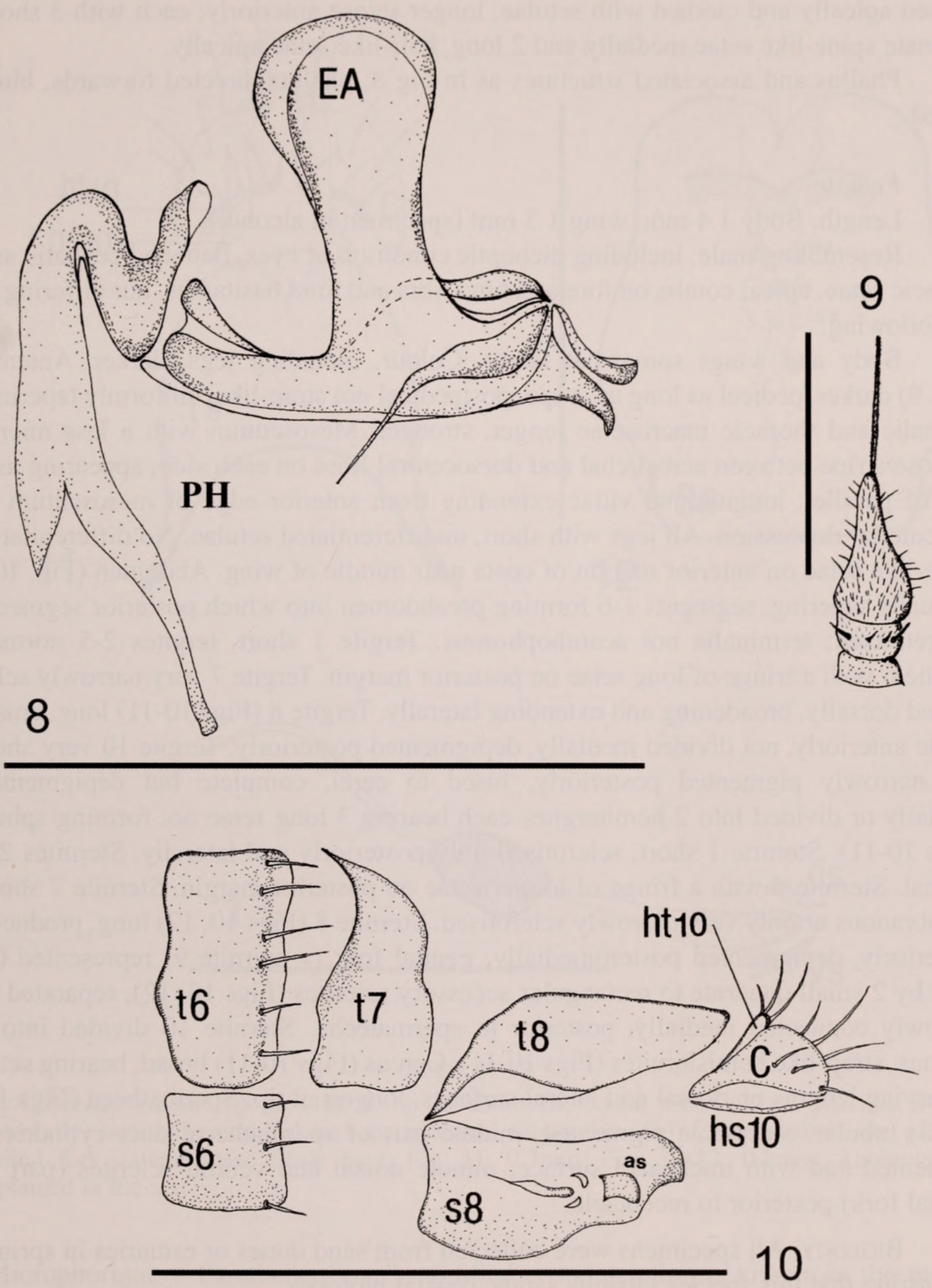

FIGS 8-10

Microphorella cassari sp. n. (8) ô phallus and associated structures, lateral view. (9) $q$ antenna, lateral view. (10) $q$ abdomen, lateral view (membranes omitted). Scale bars, Figs 8 and 9: $0.2 \mathrm{~mm}$, Fig. 10: $0.5 \mathrm{~mm}$. Abbreviations explained in the text.

lateroflexed to the right, inverted and with caudal pole directed forward, asymmetrical; hypandrium large, separated from epandrium, produced at apex and with several accessory processes, microtrichose. Cerci large, the right cercus larger, both deeply 
incised apically and clothed with setulae, longer setose anteriorly; each with 3 short, inclinate spine-like setae medially and 2 long, hair-like setae apically.

Phallus and associated structures as in Fig 8; phallus directed forwards, blunt tipped.

\section{Female}

Length. Body $1.4 \mathrm{~mm}$, wing $1.3 \mathrm{~mm}$ (specimen in alcohol).

Resembling male, including dichoptic condition of eyes, flattened cephalic and thoracic setae, apical combs on fore and hind tibia and hind basitarsus, but differing in the following:

Body and wings somewhat larger. Colour, including legs, darker. Antenna (Fig. 9) darker, pedicel as long as scape, postpedicel not strap-like, uniformly tapering. Cephalic and thoracic macrosetae longer, stronger. Mesoscutum with a less microtrichose stripe between acrostichal and dorsocentral lines on each side, appearing as a pair of parallel, longitudinal vittae extending from anterior edge of mesoscutum to prescutellar depression. All legs with short, undifferentiated setulae. No differentiated spine-like setae on anterior margin of costa near middle of wing. Abdomen (Fig. 10): gradually tapering, segments 1-6 forming preabdomen into which posterior segments are retracted; terminalia not acanthophorous. Tergite 1 short, tergites 2-5 normal. Tergite 6 with a fringe of long setae on posterior margin. Tergite 7 very narrowly sclerotised dorsally, broadening and extending laterally. Tergite 8 (Figs 10-11) long, emarginate anteriorly, not divided medially, depigmented posteriorly. Tergite 10 very short and narrowly pigmented posteriorly, fused to cerci, complete but depigmented medially or divided into 2 hemitergites each bearing 3 long setae not forming spines (Figs 10-11). Sternite 1 short, sclerotised only posteriorly and laterally. Sternites 2-5 normal. Sternite 6 with a fringe of longer setae on posterior margin. Sternite 7 short, membranous or only very narrowly sclerotised. Sternite 8 (Figs 10,12) long, produced posteriorly, depigmented posteromedially; genital fork (= sternite 9) represented (in part) by 2 small quadrate to rectangular accessory sclerites (Figs 10, 12), separated or narrowly connected medially, posterior to spermatecha. Sternite 10 divided into 2 sinuous, strap-like hemisternites (Figs 10-11). Cercus (Figs 10-11) broad, bearing setae of varying lengths on dorsal and lateral surfaces, longest at tip. Spermatheca (Figs 10, 12-13) tubular, receptacle pigmented; middle part of spermathecal duct cylindrical, pigmented and with tracheated surface; minute dorsal and ventral sclerites (part of genital fork) posterior to receptacle.

Biology: All specimens were collected from sand dunes or estuaries in spring, suggesting that this species inhabits sandy, coastal biotopes.

DisTRIBUTION: Hitherto known only from two localities - Oued Berkoukech and Oued Bouterfess - on the Tabarka embayment, northwest coast of Tunisia.

REMARKS: The new species described in this paper shows a set of remarkable morphological features. The strikingly long, strap-like, lanceolate antennal stylus of the male is unique amongst previously described species of Microphorella, both fossil and extant. The costal vein of the male bears several long, spine-like setae on the middle portion that also have not been recorded in other species of this genus. Among 

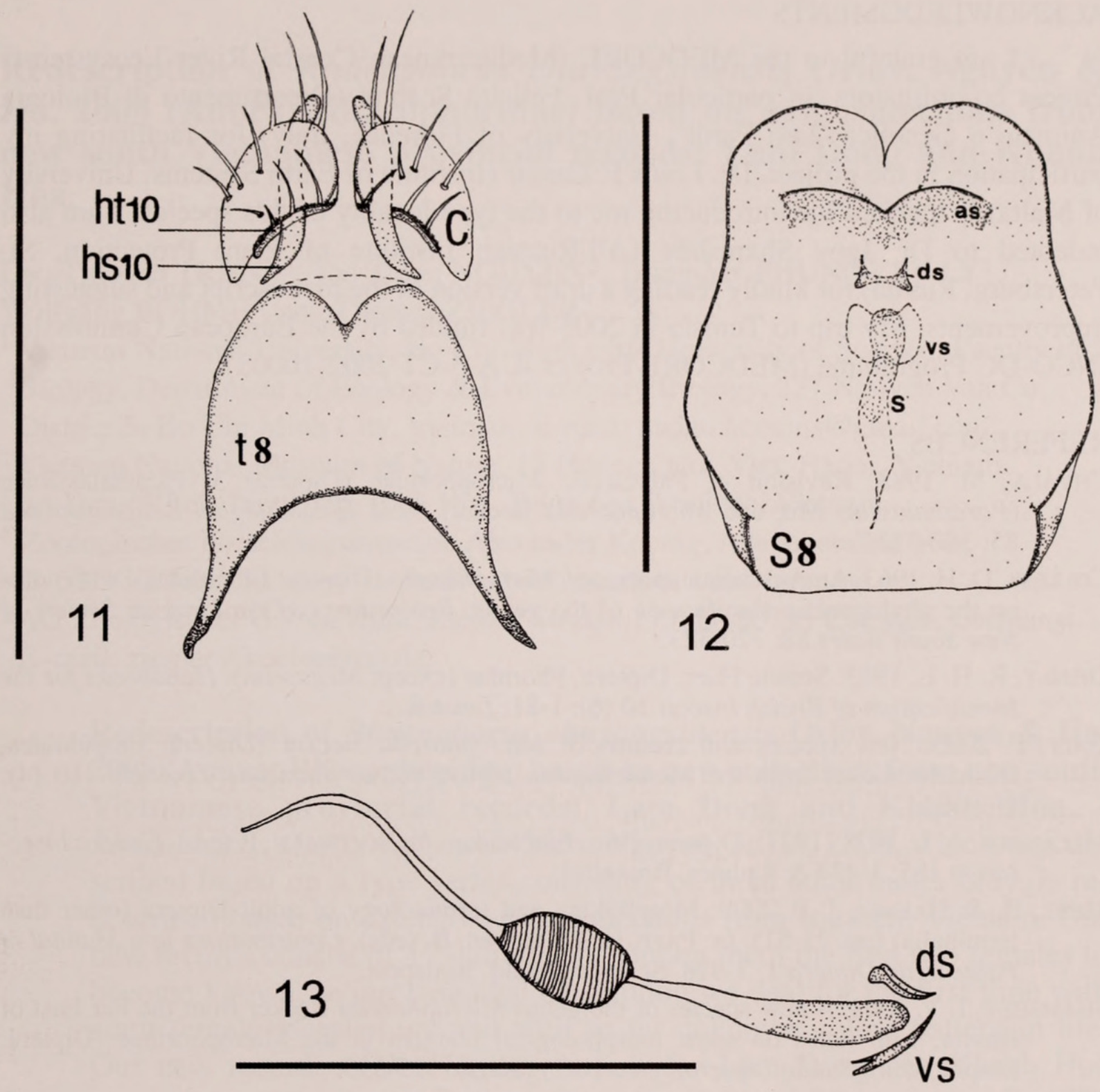

FIGS 11-13

Microphorella cassari sp. n. (11) $q$ tip of abdomen, dorsal view. (12) $q$ sternite 8 with (internally) parts of genital fork and spermatheca, dorsal view. (13) $ᄋ$ spermatheca and parts of genital fork, lateral view. Scale bars, Fig. 11: 0.3mm, Figs 12-13: 0.2mm. Abbreviations explained in the text.

"Microphorinae + Parathalassiinae" modified costal setation is known in the monotypic genus Thalassophorus Saigusa, 1986. Although divided female tergites 8 and 10 have been described, a completely divided female sternite 10 has not hitherto been reported to occur in Microphorella. Similarly, exclusively setose tergites 10 have been previously reported in only three species of Microphorella, recently described from Southeast Asia and New Guinea (Shamshev \& Grootaert, 2004).

Similar widened and flat cephalic bristles have been described and figured for Plesiothalassius capensis (Smith) by Ulrich (1991) but have not been known to occur so far in Microphorella. 


\section{ACKNOWLEDGMENTS}

I am grateful to the MEDCORE (Mediterranean Coastal River Ecosystems) Project co-ordinators, in particular Prof. Felicita Scapini (Dipartimento di Biologia Animale e Genetica 'Leo Pardi', University of Florence, Italy) for facilitating my participation in the project. Dr. Louis F. Cassar (Institute of Earth Systems, University of Malta) is thanked for introducing me to the type locality of this species. I am also indebted to Dr. Igov Shamshev (All-Russian Institute of Plant Protection, St. Petersburg, Russia) for kindly reading a draft version of the manuscript and suggesting improvements. My trip to Tunisia in 2005 was funded by the European Commission INCO-DC Programme (MEDCORE Project ICA-3-CT 2002-10003).

\section{REFERENCES}

CHVÁlA, M. 1988. Revision of Palaearctic Microphoridae (Diptera) 3. Parathalassiinae (Parathalassius Mik and Microphorella Becker). Acta Entomologica Bohemoslovaca 85: 352-372.

Colless, D. H. 1963. An Australian species of Microphorella (Diptera: Empididae), with notes on the phylogenetic significance of the genus. Proceedings of the Linnean Society of New South Wales 88: 320-323.

Disney, R. H. L. 1983. Scuttle Flies. Diptera, Phoridae (except Megaselia). Handbooks for the Identification of British Insects 10 (6): 1-81; London.

GATT, P. 2003. New species and records of Microphorella Becker (Diptera: Empidoidea, Dolichopodidae) from the Mediterranean region. Revue suisse de Zoologie 110 (4): 669-684.

Melander, A. L. 1928 (1927). Diptera, Fam. Empididae. In: Wytsman, P. (ed.). Genera insectorum 185: 1-434 \& 8 plates. Bruxelles.

MerZ, B. \& HaenNi, J. P. 2000. Morphology and terminology of adult Diptera (other than terminalia) (pp. 21-51). In: PAPP, L. \& DARVAS, B. (eds). Contributions to a Manual of Palaearctic Diptera 1: 1-978. Science Herald, Budapest.

ShamsheV, I. V. 2004. A new species of the genus Microphorella Becker from the Far East of Russia, with notes on some morphological features in the Microphorinae (Diptera: Empidoidea). Studia Dipterologica 10(2) (2003): 527-535.

Shamshev, I. V. \& Grootaert, P. 2004. Descriptions of four new species of the genus Microphorella Becker (Diptera: Empidoidea, Microphoridae, Parathalassiini) from southeast Asia and New Guinea, with notes on the relationships within the genus. The Raffles Bulletin of Zoology 52(1): 45-58.

SinClaIR, B. J. 2000. Morphology and terminology of Diptera male terminalia (pp. 53-74). In: PAPP, L. \& Darvas, B. (eds). Contributions to a Manual of Palaearctic Diptera 1: 1-978. Science Herald, Budapest.

SinclaiR, B. J. \& Cumming, J. M. 2006. The morphology, higher-level phylogeny and classification of the Empidoidea (Diptera). Zootaxa 1180: 1-172.

UlRICH, H, 1991. Two new genera of parathalassiine-like flies from South Africa (Diptera, Empodoidea). Bonner zoologische Beiträge 42(2): 187-216.

UlRICH, H. 2003. How recent are the Empidoidea of Baltic amber? Studia Dipterologica 10: 321-327. 


\section{$2 \mathrm{BHL}$ Biodiversity Heritage Library}

Gatt, Paul. 2011. "Microphorella cassari sp n., a new species of Microphorella Becker (Diptera: Dolichopodidae) from Tunisia." Revue suisse de zoologie 118, 401-412. https://doi.org/10.5962/bhl.part.117814.

View This Item Online: https://www.biodiversitylibrary.org/item/148533

DOI: https://doi.org/10.5962/bhl.part.117814

Permalink: https://www.biodiversitylibrary.org/partpdf/117814

\section{Holding Institution}

American Museum of Natural History Library

\section{Sponsored by}

BHL-SIL-FEDLINK

\section{Copyright \& Reuse}

Copyright Status: In copyright. Digitized with the permission of the rights holder.

Rights Holder: Muséum d'histoire naturelle - Ville de Genève

This document was created from content at the Biodiversity Heritage Library, the world's largest open access digital library for biodiversity literature and archives. Visit BHL at https://www.biodiversitylibrary.org. 